\title{
DETERMINAN KETERATURAN KUNJUNGAN MASA NIFAS DI PUSKESMAS TOPORE KABUPATEN MAMUJU
}

\author{
Agus Erwin Ashari ${ }^{1 凶}$, Nurdiana $^{2}$ \\ ${ }^{1}$ Jurusan Kesehatan Lingkungan Poltekkes Kemenkes Mamuju \\ ${ }^{2}$ Jurusan Kebidanan Poltekkes Kemenkes Mamuju
}

\begin{tabular}{l}
\hline ARTICLE INFO \\
\hline Article history \\
Submitted : 2020-08-24 \\
Revised : 2020-08-26 \\
Accepted : 2020-08-26 \\
Keywords: \\
Regularity of Visits \\
Postpartum \\
Education \\
Parity
\end{tabular}

\section{Kata Kunci:}

Keteraturan Kunjungan Masa Nifas Pendidikan Paritas

\begin{abstract}
The Maternal Mortality Rate in Indonesia according to SUPAS in 2015 is 305 per 100,000 live births. The number of maternal deaths in Mamuju District in 2015 was 12 people or 218 per 100,000 live births. The coverage of postpartum visits (KF3) in West Sulawesi Province tended to decline from 2012 to 2017. Post-natal visits in Mamuju District were $78.02 \%$ and in 2016 84.5\%. The research objective was to determine the determinants that affect the regularity of postpartum visits. This study used a descriptive analytic design with a cross sectional approach. The sample in this study were postpartum mothers whose postpartum period had been completed and had a KIA book in the work area of Puskesmas Topore from March to October 2018, namely 45 postpartum mothers who were selected by simple random sampling. The results showed that statistically there was no relationship between education and regular postpartum visits $(\mathrm{p}=0.613)$. There was no relationship between work and regularity of postpartum visits $(p=0.063)$, there was no relationship between parity and regularity of postpartum visits $(\mathrm{p}=0.481)$.
\end{abstract}

Angka Kematian Ibu di Indonesia menurut SUPAS tahun 2015 sebesar 305 per 100.000 kelahiran hidupan. Jumlah kematian ibu di Kabupaten Mamuju Tahun 2015 sebanyak 12 orang atau sebesar 218 per 100.000 kelahiran hidup. Cakupan kunjungan nifas (KF3) di Provinsi Sulawesi Barat cenderung menurun dari tahun 2012 sampai tahun 2017. Kunjungan Nifas di Kabupaten Mamuju sebanyak 78,02\% dan tahun 2016 sebanyak $84,5 \%$. Tujuan Penelitian adalah untuk mengetahui determinan yang mempengaruhi keteraturan kunjungan masa nifas. Penelitian ini menggunakan desain deskriptif analitik dengan pendekatan cross sectional. Sampel dalam penelitian ini adalah ibu nifas yang periode masa nifasnya telah selesai dan memiliki buku KIA di wilayah kerja Puskesmas Topore pada Bulan Maret - Oktober 2018 yaitu sebanyak 45 ibu nifas yang terpilih secara Simple Random Sampling. Hasil Penelitian menunjukkan bahwa Secara statistik tidak ada hubungan antara pendidikan dengan keteraturan kunjungan masa nifas $(\mathrm{p}=0,613)$. Tidak ada hubungan antara pekerjaan dengan keteraturan kunjungan masa nifas $(\mathrm{p}=0,063)$, tidak ada hubungan antara paritas dengan keteraturan kunjungan masa nifas $(\mathrm{p}=0,481)$.

Corresponding Author:

Agus Erwin Ashari

Jurusan Kesehatan Lingkungan Poltekkes Kemenkes Mamuju

Telp. 0811469371

Email: agus.rpjmn@gmail.com

\section{PENDAHULUAN}

Angka Kematian Ibu (AKI) adalah jumlah kematian ibu selama masa kehamilan, persalinan dan nifas yang disebabkan oleh kehamilan, persalinan, dan nifas atau pengelolaannya tetapi bukan karena sebabsebab lain seperti kecelakaan atau terjatuh di setiap 100.000 kelahiran hidup. (Kemenkes, 2018)

Angka Kematian Ibu di Indonesia menurut SUPAS tahun 2015 sebesar 305 per 100.000 kelahiran hidupan, (Kemenkes RI,
2018) Jumlah kematian ibu di Kabupaten Mamuju Tahun 2015 sebanyak 12 orang atau sebesar 218 per 100.000 kelahiran hidup (Dinkes Kab. Mamuju, 2016.)

Upaya percepatan penurunan AKI dapat dilakukan dengan menjamin agar setiap ibu mampu mengakses pelayanan kesehatan ibu yang berkualitas, seperti pelayanan kesehatan ibu hamil, pertolongan persalinan oleh tenaga kesehatan terlatih di fasilitas pelayanan kesehatan, perawatan pasca persalinan bagi ibu dan bayi, perawatan khusus dan rujukan jika 
terjadi komplikasi, kemudahan mendapatkan cuti hamil dan melahirkan, dan pelayanan keluarga berencana.

Cakupan kunjungan nifas (KF3) di Provinsi Sulawesi Barat menunjukkan kecenderungan penurunan dari tahun 2012 sampai dengan tahun 2017 masih berfluktuasi sering dengan cakupan persalinan oleh tenaga kesehatan. (Dinas Kesehatan provinsi Sulbar, 2017), demikian halnya yang terjadi di kabupaten Mamuju terjadi fluktuasi angka cakupan persalinan tenaga kesehatan dan kunjungan masa nifas. Persalinan oleh tenaga kesehatan pada tahun 2015 di Kabupaten Mamuju tercatat $80,1 \%$ dan Kunjungan Nifas (KF3) sebanyak 78,02 KN1 dan tahun 2016 sebanyak 84,5\% (Dinas Kesehatan provinsi Sulbar, 2017).

Puskesmas Topore merupakan salah satu puskesmas di kabupaten Mamuju yang angka cakupan Kunjungan masa nifas diatas rata-rata yaitu $85 \%$ pada tahun 2015 dan sebesar 89,2\%, pada tahun 2016. (Dinkes Kabupaten Mamuju, 2017). Fakta tersebut terlihat bahwa angka cakupan kunjungan masa nifas masih dibawah standar yang telah ditetapkan kementerian kesehatan. Berdasarkan fakta tersebut, maka peneliti ingin mengetahui factor yang mempengaruhi cakupan atau keteraturan kunjungan masa nifas di Puskesmas Topore. Tujuan dari penelitian adalah untuk mengetahui determinan yang mempengaruhi keteraturan kunjungan masa nifas.

\section{METODE PENELITIAN}

\section{Jenis Penelitian}

Jenis Penelitian ini adalah penelitian deskriptif analitik dengan pendekatan cross sectional, yaitu penelitian untuk mengetahui determinan yang mempengaruhi keteraturan kunjungan nifas di Puskesmas Topore.

\section{Lokasi dan Waktu Penelitian}

Lokasi penelitian di Wilayah Kerja Puskesmas Topore Kabupaten Mamuju. Waktu penelitian dilaksanakan pada Bulan Maret - Oktober Tahun 2018.

\section{Populasi dan Sampel}

Populasi dalam penelitian ini adalah seluruh ibu nifas yang periode masa nifasnya telah selesai dan memiliki buku KIA di wilayah kerja Puskesmas Topore pada bulan Maret - Oktober
2018. Sampel dalam penelitian ini adalah ibu nifas yang periode masa nifasnya telah selesai dan memiliki buku KIA di wilayah kerja Puskesmas Topore pada bulan Maret - Oktober 2018 yaitu sebanyak 45 ibu nifas yang diambil secara Total Sampling.

\section{Pengumpulan Data}

Dalam pengumpulan data, peneliti menggunakan data primer yang diperoleh melalui wawancara responden dan data sekunder yang diperoleh dari Dinas Kesehatan dan puskesmas.

\section{Pengolahan dan Analisis Data}

Data diolah dengan menggunakan Program SPSS dengan Uji Chi-Square dan disajikan dalam bentuk tabel distribusi frekuensi.

\section{HASIL PENELITIAN}

Distribusi responden pada tabel 1. berdasarkan umur tergambar bahwa kelompok umur yang terbanyak pada kelompok umur 30 34 tahun sebanyak 13 orang $(28,89 \%)$ dan yang paling sedikit pada kelompok umur $<20$ tahun sebanyak 2 orang $(4,44 \%)$. Pada tabel 1 terlihat bahwa responden terbanyak Pada kelompok kontrol tingkat pendidikan yang terbanyak adalah SD sebanyak 25 orang $(55,56 \%)$, dan yang terkecil berpendidikan DIII/S1 dan tidak tamat SD masing-masing sebanyak 1 orang $(2,22 \%)$.

Menurut pekerjaan responden, demikian halnya pada kelompok kontrol, pekerjaan responden yang terbanyak adalah Ibu Rumah Tangga sebanyak 43 orang $(95,56 \%)$. Distribusi responden menurut paritas pada kelompok kontrol yang terbanyak pada paritas $1-2$ orang sebanyak 27 orang $(60,00 \%)$ dan yang terkecil pada paritas $\geq 5$ sebanyak 2 orang $(4,44 \%)$

Pada tabel. 2 menunjukkan bahwa dari 45 responden, terdapat yang pendidikan yang cukup dan teratur melakukan kunjungan masa nifas sebanyak $15(33,3 \%)$ responden dan pendidikan cukup tetapi kunjungan masa nifas tidak teratur sebanyak $22(48,9 \%)$ responden. Hasil uji statistik dengan menggunakan uji ChiSquare dinyatakan bahwa tidak terdapat hubungan yang bermakna antara pendidikan dengan keteraturan kunjungan masa nifas dengan $p$ value $=0,613$. 
Tabel 1. Distribusi Responden menurut Karakteristik Responden di Wilayah Puskesmas Topore Kabupaten Mamuju

\begin{tabular}{lcc}
\hline \multicolumn{1}{c}{ Karakteristik Responden } & Frekuensi (n) & Persen $(\%)$ \\
\hline Umur (Tahun) & 2 & \\
$<20$ & 8 & 4,44 \\
$20-24$ & 12 & 17,78 \\
$25-29$ & 13 & 26,67 \\
$30-34$ & 9 & 28,89 \\
$35-39$ & 1 & 20,00 \\
$\geq 40$ & & 2,22 \\
Pendidikan & 1 & 2,22 \\
Tidak Sekolah & 25 & 55,56 \\
SD & 12 & 26,67 \\
SMP & 6 & 13,33 \\
SMA & 1 & 2,22 \\
Akademi & & \\
Pekerjaan & 1 & 2,22 \\
PNS & 1 & 2,22 \\
Pegawai Swasta & 43 & 95,56 \\
IRT & & \\
Paritas & 27 & 60,00 \\
$1-2$ & 16 & 35,56 \\
$3-4$ & 2 & 4,44 \\
$\geq 5$ & & \\
Keteraturan Kunjungan Masa Nifas & 17 & 37,78 \\
Teratur & 28 & 62,22 \\
Tidak Teratur & &
\end{tabular}

Dari tabel 2. juga menunjukkan bahwa dari 45 responden, terdapat yang tidak bekerja dan teratur melakukan kunjungan masa nifas sebanyak $15(33,3 \%)$ responden dan yang tidak teratur kunjungan masa nifas sebanyak 28 $(62,2 \%)$ responden. Hasil Uji statistik dengan menggunakan uji Chi-Square dinyatakan bahwa tidak terdapat hubungan yang bermakna antara pekerjaan dengan keteraturan kunjungan masa nifas dengan $p$ value $=0.063$.

Hasil penelitian menunjukkan bahwa dari 45 responden, terdapat yang paritas $1-2$ orang dan teratur melakukan kunjungan masa nifas sebanyak $10(22,2 \%)$ responden dan yang tidak teratur kunjungan masa nifas sebanyak 17 $(37,8 \%)$ responden. Hasil Uji statistik dengan menggunakan uji Chi-Square dinyatakan bahwa tidak terdapat hubungan yang bermakna antara paritas dengan keteraturan kunjungan masa nifas dengan $p$ value $=0,481$.

\section{PEMBAHASAN}

Hubungan Pendidikan dengan Keteraturan Kunjungan Masa Nifas
Hasil penelitian mengungkapkan bahwa tidak terdapat hubungan yang bermakna antara pendidikan dengan keteraturan kunjungan masa nifas dengan $p$ value $=0,613$. Hal ini sejalan dengan beberapa penelitian yang dilakukan sebelemumnya, tidak terdapat hubungan yang bermakna antara pendidikan dengan kunjungan nifas. (Ummi Trisnawati, Bahiyatun, 2013), tidak ada hubungan antara pendidikan dengan pelaksanaan PNC (Akhenan \& Puspitasari, 2011), tidak ada hubungan yang bermakna antara pendidikan dengan kunjungan nifas (Rahmawati et al., 2015).

Berbeda dengan hasil penelitian yang lain disimpulkan bahwa ada hubungan pendidikan dengan kunjungan nifas (Susanti, 2017), terdapat hubungan antara tingkat Pendidikan dan kepatuhan kunjungan nifas (Asinta Dewi Dian Silviana, 2017), ada hubungan antara Pendidikan dengan kunjungan masa nifas (Pradani \& Kurniasari, 2018), ada pengaruh Pendidikan terhadap kunjungan ibu nifas (Gita Sekar Prihanti, Juwita Rayhana, 
Widya Wahyuningtias, Anastasyia Carolina, 2019), ada hubungan pendidikan dengan pelaksanaan kunjungan masa nifas (Gustirini,
2016), ada hubungan pendidikan dengan kunjungan masa nifas (Rosita \& Kunci, 2018).

Tabel 2. Hubungan Pendidikan, Pekerjaan, dan Paritas dengan Keteraturan Kunjungan Masa Nifas di Puskesmas Topore Kabupaten Mamuju

\begin{tabular}{|c|c|c|c|c|c|c|c|}
\hline \multirow{3}{*}{ Variabel } & \multicolumn{4}{|c|}{ Keteraturan Kunjungan Masa Nifas } & \multirow{2}{*}{\multicolumn{2}{|c|}{ Total }} & \multirow{3}{*}{$\mathbf{p}$} \\
\hline & \multicolumn{2}{|c|}{ Teratur } & \multicolumn{2}{|c|}{ Tidak teratur } & & & \\
\hline & $\mathrm{n}$ & $\%$ & $n$ & $\%$ & $\mathbf{n}$ & $\%$ & \\
\hline Pendidikan & & & & & & & \multirow{5}{*}{0,613} \\
\hline Kurang & 0 & 0.0 & 1 & 2.2 & 1 & 2.2 & \\
\hline cukup & 15 & 33.3 & 22 & 48.9 & 37 & 82.2 & \\
\hline Baik & 2 & 4.4 & 5 & 11.1 & 7 & 15.6 & \\
\hline Total & 17 & 37.8 & 28 & 62.2 & 45 & 100.0 & \\
\hline \multicolumn{8}{|l|}{ Pekerjaan } \\
\hline Tidak Bekerja & 15 & 33.3 & 28 & 62.2 & 43 & 95.6 & \multirow{3}{*}{0,063} \\
\hline Bekerja & 2 & 4.4 & 0 & 0.0 & 2 & 4.4 & \\
\hline Total & 17 & 37.8 & 28 & 62.2 & 45 & 100.0 & \\
\hline \multicolumn{8}{|l|}{ Paritas } \\
\hline $1-2$ & 10 & 22.2 & 17 & 37.8 & 27 & 60.0 & \multirow{4}{*}{0,481} \\
\hline $3-4$ & 7 & 15.6 & 9 & 20.0 & 16 & 35.6 & \\
\hline$\geq 5$ & 0 & 0.0 & 2 & 4.4 & 2 & 4.4 & \\
\hline Total & 17 & 37.8 & 28 & 62.2 & 45 & 100.0 & \\
\hline
\end{tabular}

Hubungan Pekerjaan dengan Keteraturan Kunjungan Masa Nifas

Hasil penelitian menyimpulkan bahwa tidak terdapat hubungan yang bermakna antara pekerjaan dengan keteraturan kunjungan masa nifas dengan $p$ value $=0.063$. Hal ini sejalan dengan penelitian yang dilakukan Tri Pinaringsih, Emmy Riyanti (2017) bahwa tidak ada hubungan antara pekerjaan dengan niat kunjungan nifas. Hasil penelitian yang sama juga menyimpulkan bahwa tidak ada hubungan antara pekerjaan dengan pelaksanaan PNC (Akhenan \& Puspitasari, 2011), tidak ada hubungan antara pekerjaan dengan kunjungan ibu nifas. (Rahmawati et al., 2015)

\section{Hubungan Paritas dengan Keteraturan Kunjungan Masa Nifas}

Penelitian ini mengungkapkan bahwa tidak terdapat hubungan yang bermakna antara paritas dengan keteraturan kunjungan masa nifas dengan $p$ value $=0.481$. Hal ini sejalan dengan penelitian sebelumnya bahwa tidak ada hubungan antara jumlah anak dengan pelaksanaan PNC (Akhenan \& Puspitasari, 2011). Tidak ada hubungan antara jumlah anak dengan niat kunjungan nifas (Tri Pinaringsih, Emmy Riyanti, 2017). Berbeda dengan yang disimpulkan bahwa ada hubungan paritas dengan kunjungan masa nifas (Pradani \& Kurniasari, 2018), ada hubungan paritas dengan kunjungan masa nifas (Wolio, 2017), ada hubungan antara paritas dengan kunjungan masa nifas (Rosita \& Kunci, 2018).

\section{KESIMPULAN DAN SARAN}

Tidak ada hubungan antara pendidikan dengan keteraturan kunjungan masa nifas. Tidak ada hubungan antara pekerjaan dengan keteraturan kunjungan masa nifas. Tidak ada hubungan antara paritas dengan keteraturan kunjungan masa nifas.

Bagi instansi terkait disarankan untuk meningkatkan cakupan keteraturan kunjungan masa nifas melalui pendekatan dan kerja sama lintas sektor. Bagi peneliti selanjutnya disarankan untuk menggunakan variabel sikap suami, orang tua, tokoh masyarakat atau petugas kesehatan.

\section{DAFTAR PUSTAKA}

Akhenan, N. F., \& Puspitasari, N. (2011). Determinan pada ibu nifas yang berhubungan dengan pelaksanaan postnatal care. Jurnal Biometrika dan Kependudukan, 1(1), 1-10. 
http://www.journal.unair.ac.id/filerPDF/4 .Nur Fitria Akhenan dan Nunik $P$ (Volume 1 Nomor 1).pdf.

Asinta Dewi Dian Silviana, U. A. A. Y. (2017). Faktor-Faktor yang Mempengaruhi Kepatuhan Kunjungan Ibu Nifas Di Puskesmas Pandak 1 Bantul Yogyakarta. Https://Doi.Org/10.1017/CBO978110741 5324.004.

Dinas Kesehatan Provinsi Sulbar, D. K. P. (2017). Profil Kesehatan Provinsi Sulawesi Barat Tahun 2017. www.dinkes.sulbarprov.go.id.

Dinkes Kab. Mamuju, D. K. kabupaten. (n.d.). Profil Kesehatan Kabupaten Maтuju Tahun 2016.

Gita Sekar Prihanti, Juwita Rayhana, Widya Wahyuningtias, Anastasyia Carolina, A. H. (2019). Analisis Faktor Kunjungan Ibu Nifas Di Wilayah Kerja Puskesmas Poned. Jurnal Berkala Ilmiah Kedokteran Dan Kesehatan, 6(1), 69-87.

Gustirini, R. (2016). Hubungan Pendidikan dan Pengetahuan Ibu Postpartum. Masker Media, 4, 257-263.

Kemenkes, R. I. (2018). Provil Kesehatan Indonesia 2018 (Vol. 1227, Issue July). https://doi.org/10.1002/qj.

Pradani, N. N. W., \& Kurniasari, C. V. (2018). Hubungan Paritas, Umur dan Pendidikan dengan Kunjungan Nifas. Oksitosin: Jurnal Ilmiah Kebidanan, V(2), 67-78.

Rahmawati, L., Khoiri, A., \& Herawati, Y. T. (2015). Faktor yang berhubungan dengan kunjungan ibu nifas di wilayah kerja Puskesmas Jelbuk Kabupaten Jember (factor Related with Postnatal Visit in Jelbuk Community Health Center Of Jember Distric). Digital Repository Universitas Jember, 1-10.

Rosita, M., \& Kunci, K. (2018). Volume 1 , Februari 2018 Hubungan Antara Pendidikan, Usia Dan Paritas Ibu Nifas Dengan Kunjunganmasa Nifas Di Bidan Praktik Mandiri Suryati Palembang Tahun 2017. Jurnal Aisyiyah Medika.

Susanti, L. (2017). Faktor-Faktor Yang Mempengaruhi Kunjungan Masa Nifas Di Puskesmas Nagaswidak Plaju Palembang Tahun 2013. Masker Media, 5, 203-215.

Tri Pinaringsih, Emmy Riyanti, A. K. (2017). Faktor-Faktor yang Berhubungan Dengan Niat Kunjungan Ibu Nifas Ke Pelayanan Kesehatan Di Wilayah Kerja Puskesmas Tlogosari Kulon Kota Semarang. Jurnal Kesehatan Masyarakat (e-Journal), 5(3), 653-660.

Ummi Trisnawati, Bahiyatun, S. W. S. (2013). Jurnal Kebidanan Vol. 2 No. 4 April 2013 ISSN.2089-7669 Faktor Faktor yang Mempengaruhi Kunjungan Nifas di Puskesmas Jepon Kabupaten Blora Tahun 2012. Jurnal Kebidanan, 2(4), 31$34 . \quad$ https:// doi.org/10.1017/ CBO9781107415324.004.

Wolio, I. A. (2017). Faktor-faktor yang mempengaruhi Kunjungan masa Nifas yang memiliki bayi usia 2 -12 Bulan Di Wilayah Kerja Puskesmas Nambo Kota Kendari Tahun 2017. 